\title{
Review of frovatriptan in the treatment of migraine
}

\author{
Leslie Kelman \\ Headache Center of Atlanta, Atlanta, \\ GA, USA
}

\begin{abstract}
Triptans are recommended for the acute treatment of moderate to severe migraine or failure to respond to other acute migraine treatments. Seven triptans are available providing a wide range of choices. These triptans are more similar than dissimilar but patients do note differences in effectiveness and in tolerance. Also migraine situations may differ from attack to attack, providing the opportunity to exploit the uniqueness of a particular triptan. Frovatriptan has a uniquely long-half life, five times that of other triptans. This provides the opportunity to use frovatriptan in mini-prophylaxis such as in menstrual-related migraine and other situations, as well as use in long-lasting or recurrent migraine.
\end{abstract}

Keywords: frovatriptan triptans, migaine, treatment

\section{Introduction}

Migraine is a common disorder, occurring in $17 \%$ of women and $6 \%$ of men in the United States (Lipton et al 2007). Migraine disability is pervasive, for the individual, the family, and the work place (Santanello et al 2002). This is magnified by the highest prevalence occurring in the most productive and most reproductive years of life (Leonardi et al 2005). Since the initial discovery of compound GR43175 (sumatriptan) (Humphrey et al 1988), and its first tentative therapeutic publication (Doenicke et al 1988) this class of drugs, the triptans, has revolutionized the management and the lives of migraineurs. Seven different triptans are now available, some with different formulations (Lipton 1998; Silberstein 2000; Ferrari et al 2002; Rapoport et al 2003; Lucas 2006). Prescribers and consumers are seeking the "best" triptan to use. The first decision is usually based on the formulation. It is generally acknowledged that if: the headache is advanced (waking from sleep with, or due to, the migraine attack); there is early nausea or vomiting; there is rapid escalation of the migraine attack (migraine pain or associated symptoms reaching peak early in the migraine attack); or there is an urgent time line (such as pending business trip or meeting, car pooling) a formulation that reaches the brain early may required. In these situations sumatriptan subcutaneous injection or intranasal sumatriptan or zolmitriptan may by the optimum treatment. All seven triptans have oral preparations. The pharmacological actions are more similar than dissimilar. However, migraineurs frequently report differences in triptan effectiveness and adverse effects. Most of the oral triptans have similar pharmacologic properties. This review focuses on frovatriptan which has some unique pharmacological properties affording some distinct potential clinical uses.

\section{Migraine pathophysiology and the triptans}

During the past decade there has been a rapid increase in our understanding of the pathophysiology of migraine. To some extent this has been driven by attempts to better understand the mechanism of action of the triptans.

Paramount in the migraineur may be the genetic makeup. This is strongly suggested in the clinic by the high percentage of patients reporting migraine in first degree relatives (Silberstein et al 2002). A large twin epidemiological study showed a significantly 
higher concordance rate for migraine in monozygotic twins compared to dizygotic twins ( $p<0.05$ ) (Ulrich et al 1999). In $50 \%$ of families with familial hemiplegic migraine the disorder has been linked to chromosome 19p13 (Joutel et al 1994; Russell et al 1995). Other mutations have been documented in a smaller percentage of patients. However, no consistent genetic makeup has been defined in most migraine patients.

The peripheral component of the migraine process is vested in the surface vessels with surrounding trigeminal fibers, linking to the trigeminal ganglion. The trigeminal ganglion and most sensory nerves are rich in substance P (SP) and calcitonin gene related peptide (CGRP) (Uddman et al 1985). These neurotransmitters are released with activation of the trigeminal ganglion (Goadsby et al 1988) and their release may be initiated by cortical spreading depression (Moskowitz et al 1993; Ingvardsen et al 1997a, b; Ebersberger et al 2001; Goadsby 2001; Bolay et al 2002). The resulting leakage of plasma from dural blood is known as neurogenic plasma extravasation (Markowitz et al 1987) and this sterile inflammation may be responsible for the pain of migraine (Moskowitz 1990). Input from the C2 root is also part of the peripheral system (Goadsby et al 1997a).

The central component of the migraine process encompasses the trigeminal nucleus caudalis and its rostral connections. Stimulation of either the trigeminal system or $\mathrm{C} 2$ results in measurable activity in the trigeminal nucleus caudalis (Nozaki et al 1992; Kaube et al 1993; Goadsby and Hoskin 1997; Goadsby et al 1997b; Hoskin et al 1999). Information is then relayed to the thalamus; this has been demonstrated in human imaging studies where activation of the thalamus contralateral to the pain has been shown (Weiller et al 1995a).

Exerting a level of control over the above system is the central modulation of pain. PET functional scanning during treatment of migraine without aura (episodic or chronic) has shown activation of the periaqueductal grey matter (PAG), dorsal pons, and the locus coeruleus (Weiller et al 1995b; Bahra et al 2001; Matharu et al 2004; Afridi et al 2005). Stimulation of the PAG inhibits sagittal sinus-evoked trigeminal neuronal activity (Knight and Goadsby 2001), while blocking P/Q-type voltage-gated calcium channels in the PAG facilitates trigeminovascular nociceptive processing (Knight et al 2002).

"Migraine is probably caused by a combination of dysmodulation and afferent sensory activation." (Goadsby 2005). Thus, the migraine attack occurs in the genetically susceptible individual. This may be triggered by internal or external events, possibly as a result of spreading cortical depression. Subsequent activation of the peripheral mechanisms causes peripheral sensitization to occur leading to activation of the central mechanisms. This in turn may be affected by central modulation. It appears that once the central sensitization has occurred, the process may be less be amenable to the action of triptans (Burstein et al 2004).

Where then do the triptans exert their action? 1) They cause selective extracerebral intracranial vasoconstriction. 2) They inhibit trigeminal nerve terminals innervating extracerebral vessels. 3) They potentially produce central neuronal inhibition in the nucleus caudalis (Humphrey 2007).

\section{Frovatriptan pharmacology}

Cerebral vasodilatation and neurogenic inflammation are considered to be prime movers in the pathogenesis of migraine (Moskowitz 2003). Activation of 5- $\mathrm{HT}_{1 \mathrm{~B}}$ reverses cerebral vasodilatation and activation of $5-\mathrm{HT}_{1 \mathrm{D}}$ prevents neurogenic inflammation (Moskowitz 1992; Goadsby and Olesen; 1996 Longmore et al 1997). Frovatriptan like other triptans has a high affinity for $5-\mathrm{HT}_{1 \mathrm{~B}}$ and $5-\mathrm{HT}_{1 \mathrm{D}}$ receptors and a moderate affinity for the 5- $\mathrm{HT}_{1 \mathrm{~A}}$ and $5-\mathrm{HT}_{1 \mathrm{~F}}$ receptors subtypes. Frovatriptan has been shown to be one of the most potent 5$\mathrm{HT}_{1 \mathrm{~B}}$ agonists (Brown et al 1998; Stewart et al 1999). Unlike most other triptans, frovatriptan has a moderate affinity for the 5- $\mathrm{HT}_{7}$ receptors (Brown et al 1996), an action associated with coronary artery relaxation in the dog (Cushing et al 1996).

\section{Frovatriptan pharmacokinetics (Buchan 1998; Buchan et al I998, 1999; Cohen et al 1999)}

Oral bioavailability of frovatriptan is $22 \%-30 \%$ and is not affected by food. Although the maximum concentration in the plasma is achieved in 2-3 hours, $60 \%-70 \%$ of this is achieved in 1 hour. A steady state is achieved in 4-5 days. Plasma protein binding is low at $15 \%$. Higher levels are achieved in females but dosage adjustment is not required in females, older individuals or with the use of birth control. The most unique feature is the relative terminal long half-life of about 26 hours, unlike other triptans which range from 3-6 hours. Frovatriptan is chiefly metabolized by CYP1A 2 and is cleared by the kidney and liver making moderate failure of either organ not a limiting factor in treatment. Frovatriptan has a low risk of interactions with other drugs (Buchan et al 2002).

\section{Adverse effects of frovatriptan (Geraud et al 2002)}

Frovatriptin adverse effects are similar to those other triptans. Frovatriptan $2.5 \mathrm{mg}$ compared favorably to sumatriptan 
$100 \mathrm{mg}$ with comparative percentages being: dizziness 5.2 vs 5.8 , headache 3.8 vs 4.6 ; nausea 3.8 vs 7.9 ; fatigue 3.3 vs 6.0; paresthesias 2.7 vs 5.4; flushing 2.3 vs 1.0 ; temperature changes sensation 2.1 vs 3.3; abdominal pain 1.9 vs 3.5 ; dry mouth 1.5 vs 2.3 ; skeletal pain 1.5 vs 3.7 ; chest pain $1.3 \mathrm{vs}$ 2.9; somnolence 1.0 vs 2.7 ; vomiting 0.6 vs 2.5 ; asthenia 0.4 vs 2.3 ; total 36 vs 43 . The adverse effects of frovatriptin in this study were similar to placebo.

\section{Contraindications to the use of frovatriptan}

Frovatriptan, like other triptans, should not be used in patients with vascular disease including patients with cardiovascular disease, peripheral vascular disease, cerebrovascular disease, severe renal or hepatic disease, hemiplegic migraine, pregnany, lactation, and sensitivity to frovatriptan. Of note is a study of frovatriptan used in patients with coronary artery disease or risk showing no differences from placebo (Elkind et al 2004).

\section{Principles of frovatriptan use}

The principles of use of frovatriptan are the same as with other triptans. An accurate diagnosis of migraine must be made. Frovatripan should be started as early as possible in the migraine attack before the headache becomes moderate or severe (Cady et al 2004) and before central sensitization has occurred (Malick and Burstein 2000). It should be repeated after 2 hours if needed. It should not be used more than 2 days per week on a consistent basis to prevent medication overuse headache. Rescue medication for pain and nausea and vomiting should be prescribed to obviate the need for emergency room visits. If frovatriptan is not successful in acute treatment after a two headache trial, then the addition of an anti-inflammatory may be helpful. If not, then alternative triptans should be considered. Headache frequency should be minimized by using preventive medications when the frequency is high or the headaches disabling despite acute medications. Medication overuse should be avoided and detoxification initiated if needed. A bridging strategy may be needed to allow time for the preventive medication to start working. Pregnancy plans and issues should be addressed. Sleep disorders are very prevalent in migraineurs and may need to be addressed. Comorbid conditions often need to be treated concurrently with the migraine issues.

\section{Clinical use of frovatriptan}

Dose-range-finding studies have established that frovatriptan is well tolerated through the dose range of $0.5-40 \mathrm{mg}$ with the $2.5 \mathrm{mg}$ dose offering the optimal balance of efficacy and tolerability for the acute treatment of migraine (Rapoport et al 2002).

Three randomized, placebo-controlled, double-blind, parallel-group trials performed in 2676 migraineurs. Most patients were between age 30 and 50 years, had lifelong migraine for 19 years on average, averaged 3 headaches per month and one third were triptan naïve. The study established a headache response at 2 hours after frovatriptan dosing consistently greater than placebo $(\mathrm{p}<0.001)$, about twice as frequently. Headache response at 2 hours ranged from 37\%-46\% for frovatriptan compared to $21 \%-27 \%$ for placebo. At 4 hours the respective response rates were $56 \%-65 \%$ for frovatriptan and $31 \%-38 \%$ for placebo $(p<0.001)$. Time to headache response occurred within 1.5 hours in a substantial proportion of patients. Pain-free responses at 2 hours were $9 \%-14 \%$ for frovatriptan and $2 \%-3 \%$ for placebo ( $p<0.001$ ). At 4 hours pain-free responses were $27 \%-32 \%$ of patients taking frovatriptan and 9\%-14\% for the placebo group ( $\mathrm{p}<0.001$ ). It should be noted that frovatriptan has the lowest efficacy in 2-hour response, 2-hour pain free compared to the other triptans. However, $25 \%$ of patients taking frovatriptan had headache relief within 1.3-1.7 hours. The median time to headache relief was 2.3-3.8 hours for frovatriptan compared with 4.4-8.5 hours for placebo. Frovatriptan was significantly superior to placebo in relieving nausea, photophobia, and phonophobia. Frovatriptan patients returned to normal function significantly more quickly. Of the frovatriptan patients $57 \%-64 \%$ had mild or no functional impairment compared with $36 \%$ to $43 \%$ of the placebo group. The median time to meaningful relief was significantly faster for the frovatripan paitent at 6-12 hours compared with 14-17 hours $(\mathrm{p}<0.004)$. The recurrence rate was low in the range of $10 \%-25 \%$ and consistently lower than placebo with a range of $24 \%-31 \%$ (Ryan et al 2002). The 24 hours sustained response (proportion of patients with headache response at 4 hours and no recurrence in 24 hours) was $47 \%-51 \%$ of the frovatriptan patients and $22 \%-27 \%$ of the placebo patients. The mean time to recurrence for frovatriptan was 12.1-13.7 hours compared to 8.2-9.9 hours for the placebo group. Frovatriptan satisfaction was rated at $44 \%-51 \%$ compared to $17 \%-30 \%$ for placebo.

Thus like other triptans, frovatriptan is successful in providing reliable and effective treatment of the full spectrum of migraine including the associated symptoms of nausea, vomiting, photophobia, and phonophobia. In clinical practice frovatriptan, like naratriptan, is slower in onset of action than the other triptans. However, in the author's practice about one quarter to one third of patients using frovatriptan report a 
speedy onset of action and are satisfied with this triptan even with migraine attacks with rapid escalation of headache and early onset of migraine associated symptoms.

Short- and long-term use of frovatriptan $2.5 \mathrm{mg}$ studies established good tolerance by a wide range of subjects with an adverse events profile similar to that of placebo (Geraud et al 2002). Like other triptans (Allais et al 2006; Tuchman et al 2006; Mannix et al 2007a, b) frovatriptan has been shown to be effective in the short-term acute treatment of menstrual related migraine (MacGregor and Keywood 2000). However, a significant percentage of menstrual-related migraine attacks are not as amenable to routine treatment with a triptan. In these attacks the migraine may be more severe, longer lasting, less responsive to usual treatment and often recurs on repeated days during the perimenstrual phase. Options of treatment include long term prophylaxis, suppression of ovulation, or estrogen supplementation before and during the menstrual cycle, and mini-prophylaxis. Mini-prophylaxis with triptans in the perimenstrual phase has been reported to be effective (Newman et al 1998, 2001; Brandes et al 2007).

A meta-analysis of triptans suggested that headache recurrence, often a prominent feature of menstrual migraine, appears to be related to both the half-life of the triptan and the potency of the triptan agonistic action on the $5 \mathrm{HT}_{1 \mathrm{~B}}$ receptor (Géraud et al 2003). As outlined above frovatripan possesses both of these properties. A randomized, double-blind, placebocontrolled, three-way crossover study was performed in 546 women with menstrual related migraine (MRM) (Silberstein et al 2004). Patients treated each of three perimenstrual periods (PMPs) with placebo, frovatriptan $2.5 \mathrm{mg} \mathrm{qd}$, and frovatriptan $2.5 \mathrm{mg}$ bid. The 6-day treatment started 2 days before the anticipated start of MRM headache. The primary efficacy endpoint was incidence of MRM headache during the 6-day PMP. Frovatriptan was effective in reducing the incidence of menstrually related migraine in both the qd and the bid patients with bid being more effective. Both frovatriptan regimens also reduced MRM severity ( $p<0.0001$ ), duration $(\mathrm{p}<0.0001)$, and the use of rescue medication $(\mathrm{p}<0.01)$ in a dose-dependent manner. The incidence and type of adverse events for both regimens were similar to placebo and were consistent with those reported for short-term migraine management.

The success of frovatriptan in the above study raises the possibility of many opportunities for the use of frovatriptan in less conventional ways, anecdotally used, but yet to be verified in randomized, double-blind, placebo-controlled studies. The author has used frovatriptan with or without an anti-inflammatory in the following additional situations:
1) Long-duration migraines, not effectively treated by other routine triptans.

2) Recurrent migraine, occurring after initial success with other triptans but recurring the same day or repeatedly on the following days.

3) Mini-prophylaxis, to prevent migraines when known triggers for an individual which cannot be avoided such as plane flights, high altitude trips, or stressful situation such as mother-in-law visit.

4) Mini-prophylaxis, to reduce the chance of migraine during an important event such as a wedding, business meeting, or other important family or social events.

5) During the prodrome or premonitory phase of migraine (Kelman 2004), which can precede the headache and associated symptoms by many hours, to reduce or abort the subsequent full blown migraine attack.

6) In cluster headache to provide headache control for up to 7-10 days often allowing time for definitive preventive medication to become active.

\section{Conclusion}

Frovatriptan is a well-tolerated triptan, useful in clinical practice. It can be used like any other triptan but it has the additional unique property of a long half-life of 26 hours with a strong $5 \mathrm{HT}_{1 \mathrm{~B}}$ receptor agonistic action making it useful for prolonged or recurrent headaches as well as for use as in mini-prophylaxis in menstrual migraine and possibly other situations.

\section{Disclosures}

The author is a speaker for Endo Pharmaceuticals.

\section{References}

Afridi SK, Giffin NJ, Kaube H, et al. 2005. A positron emission tomographic study in spontaneous migraine. Arch Neurol, 62:1270-5.34.

Allais G, Acuto G, Cabarrocas X, et al. 2006. Efficacy and tolerability of almotriptan versus zolmitriptan for the acute treatment of menstrual migraine. Neurol Sci, 27(Suppl 2):S193-7.

Bahra A, Matharu MS, Buchel C, et al. 2001. Brainstem activation specific to migraine headache. Lancet, 357:1016-17.

Brandes JL, Smith T, Diamond M, et al. 2007. Open-label, long-term tolerability of naratriptan for short-term prevention of menstrually related migraine. Headache, 47:886-94.

Bolay H, Reuter U, Dunn AK, et al. 2002. Intrinsic brain activity triggers trigeminal meningeal afferents in a migraine model. Nat Med, $8: 136-42$.

Brown AM, Ho M, Thomas DR, et al. 1998. Comparison of functional effects of frovatriptan (VML 251), sumatriptan, and naratriptan on human recombinant 5-HT1 and 5-HT7 receptors [abstract]. Headache, 38:376.

Brown AM, Parsons AA, Raval P, et al. 1996. SB 209509 (VML 251), a potent constrictor of rabbit basilar artery with high affinity and selectivity for human 5-HT1D receptors [abstract]. Br J Pharmacol, 119(Suppl):110P. 
Buchan P. 1998. The pharmacokinetics of frovatriptan (VML 251/SB 209509), a potent selective 5-HT1B/1D agonist, following single dose administration by oral and intravenous routes to healthy male and female volunteers [abstract]. Headache, 38:376.

Buchan P, Keywood C, Ward C. 1998. Pharmacokinetics of Frovatriptan (VML 251/SB 209509) in healthy young and elderly male and female subjects [abstract]. Cephalalgia, 18:410.

Buchan P, Wade A, Ward C, et al. 2002. Frovatriptan: a review of drug-drug interactions. Headache, 42(Suppl 2):S63-73.

Buchan P, Ward C, Zeig S. 1999. Frovatriptan pharmacokinetics are unaffected during a migraine attack [abstract]. Cephalalgia, 19:365.

Burstein R, Collins B, Jakubowski M. 2004. Defeating migraine pain with triptans: a race against the development of cutaneous allodynia. Ann Neurol, 55:19-26.

Cady R, Elkind A, Goldstein J, et al. 2004. Randomized, placebo-controlled comparison of early use of frovatriptan in a migraine attack versus dosing after the headache has become moderate or severe. Curr Med Res Opin, 20:1465-72.

Cohen AF, van der Post J, Sacks, et al. 1999. Pharmacokinetics of frovatriptan in patients with renal impairment [abstract]. Cephalalgia, 19:365.

Cushing DJ, Zgombick JM, Nelson DL, et al. 1996. LY215840, a highaffinity 5-HT7 receptor ligand, blocks serotonin-induced relaxation in canine coronary artery. J Pharmacol Exp Ther, 277:1560-6.

Doenicke A, Brand J, Perrin VL. 1988. Possible benefit of GR43175, a novel 5-HT1-like receptor agonist, for the acute treatment of severe migraine. Lancet, 11:1309-11.

Ebersberger A, Schaible H-G, Averbeck B, et al. 2001. Is there a correlation between spreading depression, neurogenic inflammation, and nociception that might cause migraine headache? Ann Neurol, 41:7-13.

Elkind AH, Satin LZ, Nila A, et al. 2004. Frovatriptan use in migraineurs with or at high risk of coronary artery disease. Headache, 44:403-10.

Ferrari MD, Goadsby PJ, Roon KI, et al. 2002. Triptans (serotonin 5HT1B/1D agonists) in migraine: detailed results and methods of a meta-analysis of 53 trials. Cephalalgia, 22:633-8.

Géraud G, Keywood C, Senard JM. 2003. Migraine headache recurrence: relationship to clinical, pharmacological, and pharmacokinetic properties of triptans. Headache, 43:376-88

Geraud G, Spierings EL, Keywood C. 2002. Tolerability and safety of frovatriptan with short- and long-term use for treatment of migraine and in comparison with sumatriptan. Headache, 42(Suppl 2):S93-9.

Goadsby PJ. 2001. Migraine, aura and cortical spreading depression: why are we still talking about it? Ann Neurol, 49:4-6.

Goadsby PJ. 2005. Migraine pathophysiology. Headache, 45(Suppl 1): S14-24.

Goadsby PJ, Edvinsson L, Ekman R. 1988. Release of vasoactive peptides in the extracerebral circulation of man and the cat during activation of the trigeminovascular system. Ann Neurol, 23:193-6.

Goadsby PJ, Hoskin KL. 1997. The distribution of trigeminovascular afferents in the nonhuman primate brain Macaca nemestrina: a c-fos immunocytochemical study. J Anat, 190:367-75.

Goadsby PJ, Hoskin KL, Knight YE. 1997a. Stimulation of the greater occipital nerve increases metabolic activity in the trigeminal nucleus caudalis and cervical dorsal horn of the cat. Pain, 73:23-8.

Goadsby PJ, Hoskin KL, Knight YE. 1997b. Stimulation of the greater occipital nerve increases metabolic activity in the trigeminal nucleus caudalis and cervical dorsal horn of the cat. Pain, 73:23-8.

Goadsby PJ, Olesen J. 1996. Diagnosis and management of migraine. BMJ, 312:1279-83.

Hoskin KL, Zagami A, Goadsby PJ. 1999. Stimulation of the middle meningeal artery leads to Fos expression in the trigeminocervical nucleus: a comparative study of monkey and cat. $J$ Anat, 194:579-88.

Humphrey PP. 2007. The discovery of a new drug class for the acute treatment of migraine. Headache, 47(Suppl 1):S10-9.

Humphrey PP, Feniuk W, Perren MJ, et al. 1988. GR43175, a selective agonist for the 5-HT1-like receptor in dog isolated saphenous vein. Br J Pharmacol, 94:1123-32.
Ingvardsen BK, Laursen H, Olsen UB, et al. 1997a. Possible mechanism of c-fos expression in trigeminal nucleus caudalis following spreading depression. Pain, 72:407-15.

Ingvardsen BK, Laursen H, Olsen UB, et al. 1997b. Comment on Ingvardsen et al. Pain, 72:407-15. Reply to Moskowitz et al. Pain, 1998; 76:266-7.

Joutel A, Ducros A, Vahedi K, et al. 1994. Genetic heterogeneity of familial hemiplegic migraine. Am J Hum Genet, 55:1166-72.

Kaube H, Keay KA, Hoskin KL, et al. 1993. Expression of c-Fos-like immunoreactivity in the caudal medulla and upper cervical cord following stimulation of the superior sagittal sinus in the cat. Brain Res, 629:95-102.40.

Kelman L. 2004. The premonitory symptoms (prodrome): a tertiary care study of 893 migraineurs. Headache, 44:865-72.

Knight YE, Bartsch T, Kaube H, et al. 2002. P/Q-type calcium channel blockade in the PAG facilitates trigeminal nociception: a functional genetic link for migraine? J Neurosci, 22:RC213.

Knight YE, Goadsby PJ. 2001. The periaqueductal gray matter modulates trigeminovascular input: a role in migraine? Neurosci, 106:793-800.

Leonardi M, Steiner TJ, Scher AT, Lipton RB. 2005. The global burden of migraine: measuring disability in headache disorders with WHO's Classification of Functioning, Disability and Health (ICF). J Headache Pain, 6:429-40.

Lipton RB. 1998. Disability assessment as a basis for stratified care. Cephalalgia, 18(Suppl 22):40-43.

Lipton RB, Bigal ME, Diamond M, et al. 2007. Migraine prevalence, disease burden, and the need for preventive therapy. Neurology, 68:343-9.

Longmore J, Shaw D, Smith D, et al. 1997. Differential distribution of 5-HT1D- and 5-HT1B-immunoreactivity within the human trigeminocerebrovascular system: implications for the discovery of new antimigraine drugs. Cephalalgia, 17:833-842.

Lucas C. 2006. Strategies to improve migraine treatment results. Drugs, 66(Suppl 3):9-16.

MacGregor EA, Keywood C. 2000. Frovatriptan is effective in menstrually associated migraine. Cephalalgia, 20:345.

Malick A, Burstein R. 2000. Peripheral and central sensitization during migraine. Funct Neurol, 15(Suppl 3):28-35.

Mannix LK, Loder E, Nett R, et al. 2007a. Rizatriptan for the acute treatment of ICHD-II proposed menstrual migraine: two prospective, randomized, placebo-controlled, double-blind studies. Cephalalgia, 27:414-21.

Mannix LK, Savani N, Landy S, et al. 2007b. Efficacy and tolerability of naratriptan for short-term prevention of menstrually related migraine: data from two randomized, double-blind, placebo-controlled studies. Headache, 47:1037-49.

Matharu MS, Bartsch T, Ward N, et al. 2004. Central neuromodulation in chronic migraine patients with suboccipital stimulators: a PET study. Brain, 127:220-30.

Markowitz S, Saito K, Moskowitz MA. 1987. Neurogenically mediated leakage of plasma proteins occurs from blood vessels in dura mater but not brain. $J$ Neurosci, 7:4129-36.

Moskowitz MA. 1990. Basic mechanisms in vascular headache. Neurol Clin, 8:801-15.

Moskowitz MA. 1992. Neurogenic versus vascular mechanisms of sumatriptan and ergot alkaloids in migraine. Trends Pharmacol Sci, 13:307-11.

Moskowitz MA. 1993. Neurogenic inflammation in the pathophysiology and treatment of migraine. Neurology, 6(Suppl 3):S16-20.

Moskowitz MA, Nozaki K, Kraig RP. 1993. Neocortical spreading depression provokes the expression of C-fos protein-like immunoreactivity within the trigeminal nucleus caudalis via trigeminovascular mechanisms. J Neurosci, 13:1167-77.

Newman LC, Lipton RB, Lay CL, et al. 1998. A pilot study of oral sumatriptan as intermittent prophylaxis of menstruation-related migraine. Neurology, 51:307-9.

Newman L, Mannix LK, Landy S, et al. 2001. Naratriptan as short-term prophylaxis of menstrually associated migraine: a randomized, doubleblind, placebo-controlled study. Headache, 413:248-56. 
Nozaki K, Boccalini P, Moskowitz MA. 1992. Expression of c-fos-like immunoreactivity in brainstem after meningeal irritation by blood in the subarachnoid space. Neuroscience, 49:669-80.

Rapoport A, Ryan R, Goldstein J, et al. 2002. Dose range-finding studies with frovatriptan in the acute treatment of migraine. Headache, 42(Suppl 2):S74-83.

Rapoport AM, Tepper SJ, Bigal ME, et al. 2003 The triptan formulations. How to match patients and products. CNS Drugs, 17:431-47.

Russell MB, Iselius L, Olesen J. 1995. Investigation of the inheritance of migraine by complex segregation analysis. Hum Genet, 96:726-30.

Ryan R, Geraud G, Goldstein J, et al. 2002. Clinical efficacy of frovatriptan: placebo-controlled studies. Headache, 42(Suppl 2):S84-92.

Santanello NC, Davies G, Allen C, et al. 2002. Determinants of migrainespecific quality of life. Cephalalgia, 22:680-5.

Silberstein SD. 2000. Practice parameter: evidence-based guidelines for migraine headache (an evidence-based review). Report of the Quality Standards Subcommittee of the American Academy of Neurology. Neurology, 55:754-62.

Silberstein SD, Elkind AH, Schreiber C, et al. 2004. A randomized trial of frovatriptan for the intermittent prevention of menstrual migraine. Neurology, 27:261-9.

Silberstein SD, Lipton RB, Goadsby PJ. 2002. Headache in Clinical Practice. 2nd ed. London, UK: Martin Dunitz.

Stewart M, Napier CM, Katugampola SD, et al. 1999. The binding affinity and functional activity of eletriptan and other 5-HT1B/1D agonists at the human recombinant 5-HT1B and 5-HT1D receptors [abstract]. Br J Pharmacol, 127:93P.

Tuchman M, Hee A, Emeribe U, et al. 2006. Efficacy and tolerability of zolmitriptan oral tablet in the acute treatment of menstrual migraine. CNS Drugs, 20:1019-26.

Uddman R, Edvinsson L, Ekman R, et al. 1985. Innervation of the feline cerebral vasculature by nerve fibers containing calcitonin gene-related peptide: trigeminal origin and co-existence with substance P. Neurosci Lett, 62:131-6.

Ulrich V, Gervil M, Kyvik KO, et al. 1999. Evidence of a genetic factor in migraine with aura: a population based Danish twin study. Ann Neurol, 45:242-6.

Weiller C, May A, Limmroth V, et al. 1995a. Brain stem activation in spontaneous human migraine attacks. Nat Med, 1:658-60.

Weiller C, May A, Limmroth V, et al. 1995b. Brain stem activation in spontaneous human migraine attacks. Nat Med, 1:658-60. 